\title{
Análise integrada do nível de água subterrânea e superficial na região da barragem de Bocaina
}

\section{Juliana Maria de Morais Sobreira Valença Jaime Joaquim da Silva Pereira Cabral Sylvana Melo dos Santos Gastão Fonseca Neto Margarita Lopez Gil}

\section{RESUMO}

A escassez da água, a gestão e caracterização de aquíferos e águas superficiais são fatores determinantes nos estudos associados à sustentabilidade de recursos hídricos. No semiárido brasileiro, região com secas severas e abastecimento vinculado a barragens e aos manaciais subterrâneos, a importância desse estudo consiste na investigaçáo destes componentes, principalmente pela nessecidade de informaçóes que contribuam para uma gestão integrada desses recursos, como estabelece o Conselho Nacional de Recursos Hídricos (CNRH) através das diretrizes da Resolução no 15, de 12/01/2001. Dessa maneira, o objetivo dessa pesquisa é analisar de forma associada a relação entre o comportamento dos níveis d'água da Barragem de Bocaina e dos aquíferos da região sob a influência da precipitaçáo. Como metodologia, foram realizados monitoramentos dos níveis de água em poços existentes na região, da variação de volume da Barragem, bem como dos dados de precipitação da bacia durante os anos de 2013, 2014 e 2015. Os resultados da pesquisa mostram comportamentos semelhantes nas variaçôes dos níveis dos poços e dos níveis da água no reservatório, influenciados pela distribuição da precipitação, características dos solos e elevação do terreno. Essa análise apresenta ainda correlação entre os diferentes pontos de água, concluindo que a gestão de recursos hídricos na região deve analisar de forma integrada a pluviometria, o nível de água na barragem e o nível piezométrico dos poços.

Palavras-chave: águas subterrâneas, precipitação, barragem Bocaina
Submetido em: 02/10/17

Revisado em: 27/12/17

Aprovado em: 30/12/17

\section{ABSTRACT}

Water scarcity, management and characterization of aquifers and surface waters are determining factors in the studies associated to the sustainability of water resources. In the Brazilian semiarid region, a region with severe droughts and supply linked to dams and underground manacles, the importance of this study consists in the investigation of these components, mainly by the information that contributes to an integrated management of these resources, as established by the National Council of Water Resources (CNRH) through the guidelines of Resolution 15 of January 12,2001 . In this way, the objective of this research is to analyze in an associated way the relationship between the water levels of the Bocaina dam and the aquifers of the region under the influence of precipitation. As a methodology, monitoring of the water levels in existing wells in the region, the volume variation of the dam, as well as the basin precipitation data during the years of 2013, 2014 and 2015 were carried out. The search results show similar behaviors in the variations well levels and water levels in the reservoir, influenced by the precipitation distribution, soil characteristics and terrain elevation. This analysis also shows a correlation between the different water points, concluding that the management of water resources in the region should analyze in an integrated way the rainfall, the level of water in the dam and the piezometric level of the wells.

Keywords: groundwater, precipitation, Bocaina dam

\section{INTRODUÇÃO}

Com a crise hídrica no mundo, muitos estudos têm norteado políticas de outorga e uso sustentável da água.
As regióes semiáridas sofrem com baixos índices pluviométricos associados a uma demanda hídrica crescente. Nesse contexto, avaliar a interação entre precipitação, nível dos reservatórios e águas subterrâneas, torna-se 
uma ferramenta importante para orientaçáo de governo e população na implementação de rotinas adequadas aos objetivos de preservação para geraçóes futuras.

Analisar os corpos hídricos superficiais e subterrâneos de forma integrada norteia de forma significativa esse estudo, visto que a interdependência desses recursos influencia a capacidade de recuperação de seus volumes na dinâmica hidrológica. A importância desse estudo está nessa visualização conjunta que entrega resultados que facilitam o entendimento da continuidade e interação dos seus comportamentos.

As águas subterrâneas e superficiais apresentam conexóes de modo que o uso de um, tem efeito sobre o outro. Com isso, é fundamental o conhecimento das interaçôes dessas águas para o gerenciamento sustentável desses recursos (MARTELLI, 2012), mesmo que, admitindo que a água de superfície seja conectada hidraulicamente às águas subterrâneas, as interaçôes são difíceis de observar e medir, e geralmente são ignoradas nas consideraçóes e políticas de gerenciamento de água (WINTER et al., 1988). Deste modo, num cenário que agrega recursos hídricos superficiais e subterrâneos, avaliá-los separadamente representa, além de uma simplificação, uma limitação na efetiva solução dos problemas (ZOBY; MATOS, 2002). O entendimento das relaçôes e conexôes depende, prioritariamente, da caracterização da resposta dos aquíferos em função das variáveis climáticas, das características hidrogeológicas in situ e do uso e ocupaçáo da terra (MANZIONE, 2015). Bem como, o monitoramento da profundidade do nível da água é uma estratégia importante no planejamento e gestão de águas subterrâneas em áreas afetadas pela sazonalidade das chuvas. Isso, considerando que quando os fenômenos El Niño e La Nińa são estudados separadamente, verifica-se uma tendência de aumento da recarga quando há um aumento na intensidade do fenômeno El Nińo, e uma diminuição da recarga quando há um aumento da intensidade do fenômeno La Nińa (MARCUZZO; MANZIONE; WENDLAND, 2012; MARCUZZO; TROIAN; GOFFERMANN, 2012). Ainda de acordo com Mestrinho (2008), considerando as funçóes das águas subterrâneas (social, ambiental e econômica), estratégias eficientes de monitoramento devem envolver o controle da qualidade e quantidade, levando em conta as inter-relaçóes com as águas superficiais, condiçóes climáticas e usos locais.
Entende-se como Gerenciamento Integrado o resultado dos comportamentos complementares dos recursos hídricos. Se, por um lado, os corpos d'água superficiais são mais vulneráveis à poluição e às perdas por evaporação, apesar de maior facilidade de exploração, os aquíferos são bastante limitados em relação à recarga anual, mesmo em anos chuvosos. Fundamentando, assim, a água subterrânea como reserva estratégica em épocas de escassez hídrica. A grande capacidade de armazenamento e resistência contra longos períodos de estiagem fazem dos recursos hídricos subterrâneos um grande aliado na redução dos estresses hídricos que populaçôes têm enfrentado ou ainda enfrentarão (HIRATA et al., 2010). Complementarmente, sua explotação, onde, racionalmente planificada conduz a uma otimizaçáo do aproveitamento dos recursos hídricos subterrâneos (FEITOSA, E.; FEITOSA, F., 2008).

Como mostrado por Tucci (1993), a precipitação de menor intensidade ao atingir o solo permitirá que toda água penetre ocorrendo uma diminuição progressiva na capacidade de infiltração, já que o solo está se saturando. A grande variabilidade temporal e espacial da infiltração numa grande bacia hidrográfica conduz à necessidade de estudar as respostas do volume armazenado no aquífero após períodos secos e chuvosos, com vistas ao entendimento do comportamento padrão de recuperação do mesmo. Nesse contexto, vários estudos sugerem que o aumento da precipitação anual equivale a uma maior recarga anual de água subterrânea (JYRKAMA; SYKES, 2007; ALLEN et al., 2010). E considerando a topografia e a estrutura geológica, a recarga de alguns aquíferos está relacionada à variabilidade da precipitação e mudanças climáticas, por isso, dispor uma base de dados hidroclimáticas é crucial para gestão dos recursos hídricos (LORENZO-LACRUZ; GARCIA; MORÁN-TEJEDA, 2017).

$\mathrm{Na}$ região semiárida do Piauí onde a população enfrenta restriçôes hídricas e considera as reservas hídricas subterrâneas como estratégicas, o entendimento de uso sustentável destas águas abrange os ecossistemas circunvizinhos, idealizando uma preservação conjunta de ambientes subterrâneos e superficiais.

Na bacia do rio Parnaíba, mais de $90 \%$ de sua geologia é formada por bacias sedimentares com grande potencial aquífero, representada, principalmente, pelos 
aquíferos Serra Grande $\left(24 \mathrm{~m}^{3} / \mathrm{s}\right.$ de reserva potencial explotável), Cabeças $\left(15 \mathrm{~m}^{3} / \mathrm{s}\right)$ e Poti-Piauí $\left(182 \mathrm{~m}^{3} / \mathrm{s}\right)$ (ANA, 2016).

O uso das águas exploradas do aqüífero Serra Grande são atividades de subsistência, de caráter doméstico, sendo os poços particulares explorados por pequenas comunidades, na maioria dos casos, por intermédio de chafarizes. Em percentuais, o uso primordial é a irrigaçăo com $21,17 \%$, o abastecimento urbano com $16,57 \%$ e a atividade pecuária com $7,53 \%$ do total dos poços (ANDRADE JÚNIOR et al., 2003).

Com potencial para abastecimento da região, o estudo do monitoramento do nível de água armazenada no aquífero Serra Grande integrado ao comportamento do volume da Barragem, decorrentes da precipitaçáo, têm fundamental importância para idealizar mecanismose procedimentos de uso sustentável desse sistema hídrico. Desse modo, o estudo em questáo tem o objetivo de realizar uma análise integrada das variaçóes dos níveis de água subterrânea e da Barragem de Bocaina durante três anos, e do impacto causado ano a ano nos corpos hídricos da região.

\section{ÁREA DE ESTUDO}

A Barragem de Bocaina localiza-se na Bacia Hidrográfica do Rio Guaribas, sudeste piauiense, regiâo semiárida do Nordeste do Brasil, situada entre os paralelos $6^{\circ} 28^{\prime}$ e $7^{\circ} 17^{\prime}$ de latitude sul e $40^{\circ} 47^{\prime}$ e $41^{\circ} 40^{\prime}$ de longitude oeste (Figura 1). O rio Guaribas nasce na Serra das Almas, a $600 \mathrm{~m}$ de altitude tendo como seus principais afluentes os rios Canabrava e Pitombeiras, pela margem direita e Grotão, Riachão e São João, pela margem esquerda. Apresenta níveis críticos de disponibilidade hídrica com extrema irregularidade de chuvas que se concentram praticamente entre três ou quatro meses do ano.

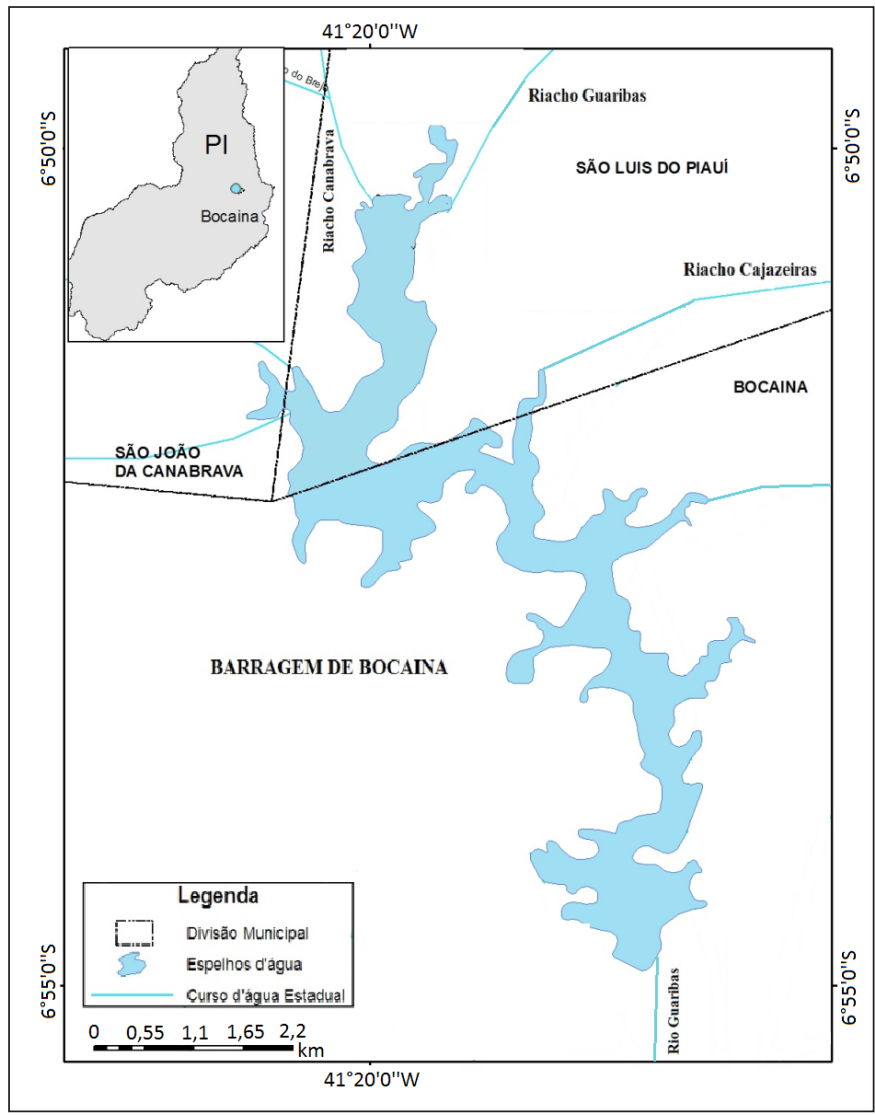

Figura 1 - Localização da Barragem de Bocaina 
O rio Guaribas tem suas aluvióes contribuindo para fornecimento de água, principalmente para as culturas de vazante, sendo temporário, com fluxo superficial somente no período chuvoso; mas segundo Cruz e França (1967) ele parece ser realimentado pelos aquíferos Pimenteiras e Serra Grande.

O Reservatório de Bocaina, que atravessa as cidades de Bocaina, Sussuapara e Picos têm área de drenagem em torno de $1.071 \mathrm{~km}^{2}$ e capacidade de 106 milhôes de $\mathrm{m}^{3}$. Foi construído sob a responsabilidade do Departamento Nacional de Obras Contra as Secas (DNOCS) e executado pelo Batalhão de Engenharia e Construção, com os objetivos de regularizar o Rio Guaribas, oferecer segurança hídrica para população e preservar o aquífero Serra Grande.

Atualmente, há que se mencionar a construção do Sistema Adutor Bocaina que prevê o abastecimento das cidades de Bocaina, Sussuapara e parte da população de Picos, com populaçáo total de projeto estimada para o ano de 2041 de 98.464 habitantes. A captação de água bruta será realizada no espelho d'água do lago formado pela Barragem Bocaina com vazão de projeto a ser captada de $300,00 \mathrm{~L} / \mathrm{s}$ e extensão total de 29.979,63 m (PIAUÍ, 2016).

Esta região é caracterizada por minifúndios que produzem, principalmente, culturas de banana, goiaba e arroz, e pela psicultura no lago da barragem. Sendo marcada por conflitos entre esses usuários. Os que estáo imediatamente à jusante pleiteiam pouca abertura na válvula da tomada d'água da Barragem para evitar a inundação das culturas e, os que estão logo em seguida, solicitam uma maior abertura para garantir a perenização do Rio Guaribas. Com o uso da água da Barragem para piscicultura intensiva, em época de estiagem, mais um conflito se instalou com a exigência dos piscicultores para que houvesse diminuição da vazão liberada para permanência da profundidade necessária à criação dos peixes.

Outro aspecto relevante na região é o intenso rebaixamento do nível potenciométrico no Aquífero Serra Grande, onde estudos mostram com base nos dados históricos de demanda e volume explorado, o rebaixamento de até 26,9 metros, ao longo de 43 anos, na zona urbana do município de Picos (VIDAL, 2003).

\section{GEOLOGIA E HIDROGEOLOGIA LOCAL}

O relevo da região apresenta-se essencialmente modelado em rochas sedimentares argilo-arenosas e arenosas, com topografia ondulada, dissecada em formas tabulares, com ocorrência de um relevo em forma de cuestas. Os processos de erosão estão desenvolvidos e as vertentes se alargam formando vales abertos.

Todas as formaçóes que ocorrem na bacia da Barragem Bocaina possibilitam a exploração da água subterrânea. O principal aquífero da região estudada é representado pelo sistema Serra Grande, confinado pela Formação Pimenteiras (Figura 2). A Formação Pimenteiras tem características de um aquitardo, que armazena pequena quantidade de água nos arenitos intercalados com folhelhos e siltitos argilosos, mas, de acordo com Cruz e França (1967), a qualidade de suas águas é muito inferior à do aquífero Serra Grande. A Formação Cabeças é outro importante aquífero e sua área de recarga localiza-se a oeste da área discutida neste trabalho.

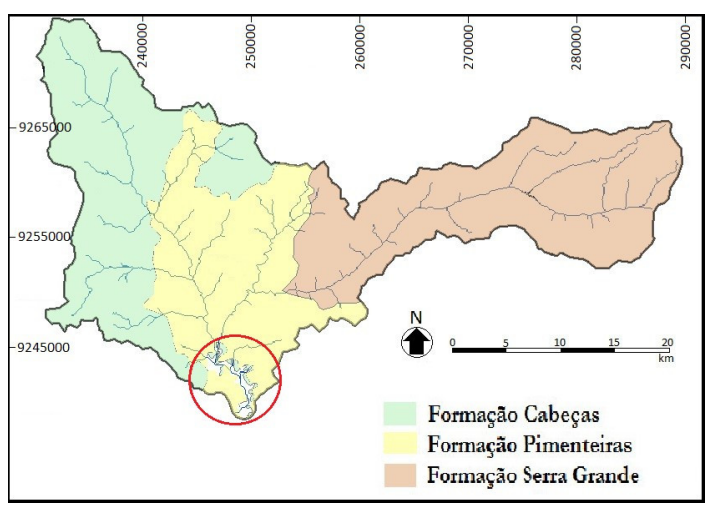

Figura 2 - Áreas de afloramento das Formações Geológicas na área da Barragem de Bocaina (em destaque) - Bacia do Rio Guaribas.

A Barragem Bocaina está assentada sobre os sedimentos aflorantes da porção superior da Formação Pimenteiras sobreposta à Formação Serra Grande conforme corte das unidades litoestratigráficas da regiâo nas Figuras 2 e 3 (VASCONCELOS et al., 2014). 


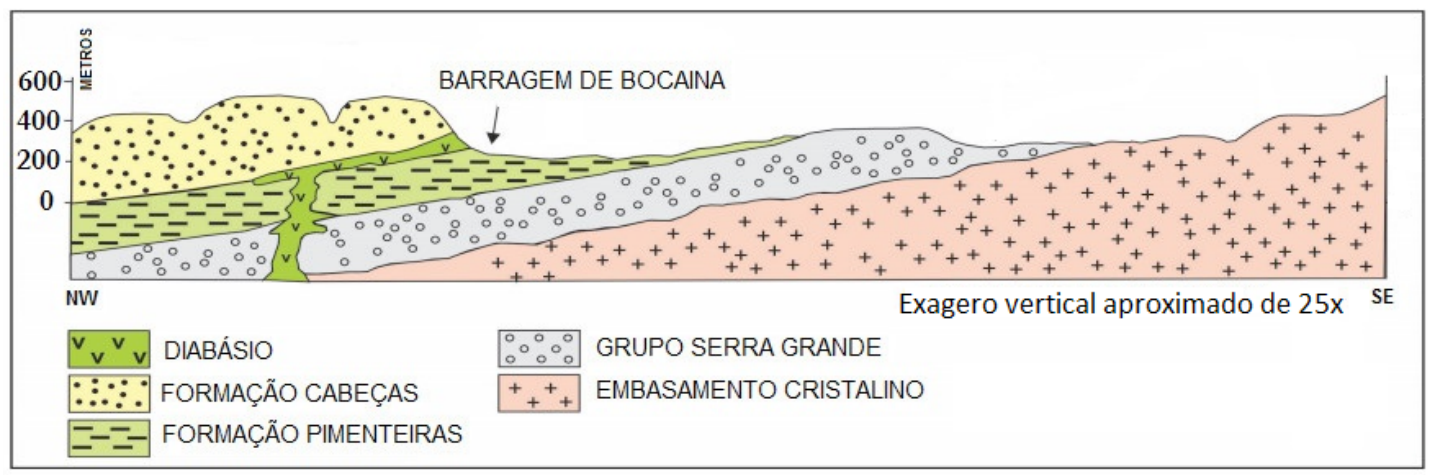

Figura 3 - Corte esquemático das unidades litoestratigráficas na bacia do Parnaíba - adaptado de Cruz e França (1967)

A coluna estratigráfica da bacia do Parnaíba na região estudada compreende os clásticos da Formação Serra Grande, depositados talvez entre o ordoviciano ou eo-siluriano e o devoniano inferior, constituída por arenitos de cores claras, mal selecionados, frequentemente conglomeráticos e com estratificação cruzada, de folhelhos escuros, conforme estabelecido por Mesner e Wooldridge (1964).

Recobrindo concordantemente a Formação Serra Grande, a Formação Pimenteiras é constituída por dois membros distintos: o inferior, arenoso (membro Itaim), e o superior, rico em folhelhos (KEGEL, 1953; MESNER; WOOLDRIDGE, 1964).

A espessura exata desses sedimentos na regiáo ainda não foi definida. Com base em estudos e nos dados do poço mais profundo da região, acredita-se que a espessura da Formação Serra Grande na área possa alcançar mais de 350 metros e a Formação Pimenteiras varie até 246 metros quando é recoberta pela Formação Cabeças (CRUZ; FRANÇA, 1967).

Para melhor entendimento das formaçóes geológicas, foram considerados três poços cadastrados no Sistema de Informaçóes de Água Subterrânea SIAGAS, da CPRM, nos municípios de Bocaina e São João da Canabrava, na região da Barragem de Bocaina, nomeados P1 SIAGAS, P2 SIAGAS e P3 SIAGAS (Figura 4). Os demais poços foram utilizados para o monitoramento dos níveis de água subterrânea. Os perfis dos poços SIAGAS estão mostrados na Figura 5 e dão uma idéia da espessura da Formação Pimenteiras ao longo da direção OesteLeste da Barragem.

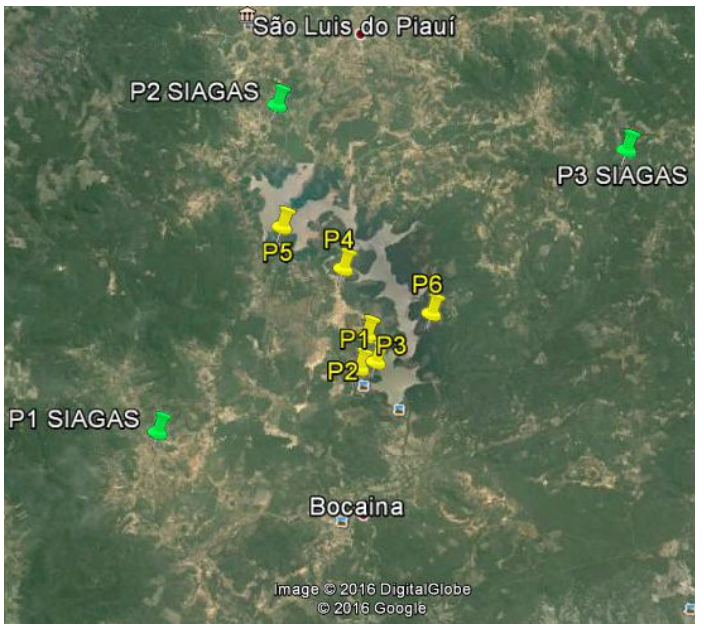

Figura 4 - Localização dos poços de monitoramento (P1 a P6) e dos poços obtidos no SIAGAS

De acordo com o detalhamento dos perfis dos poços é possível observar que a Formação Pimenteiras descreve, na área em estudo, uma superfície com menor espessura a leste da Barragem atingindo maiores profundidades a oeste, confinando a formação Serra Grande. Esta com área de afloramento a leste da área em estudo.

A análise das potencialidades hídricas de cada formação destaca o aquífero Serra Grande como o principal aquífero da região, pois tem condiçôes de atender as demandas hídricas locais, não apresentando restrição para implantação e/ou ampliação de sistemas de abastecimento de água na zona urbana e rural 


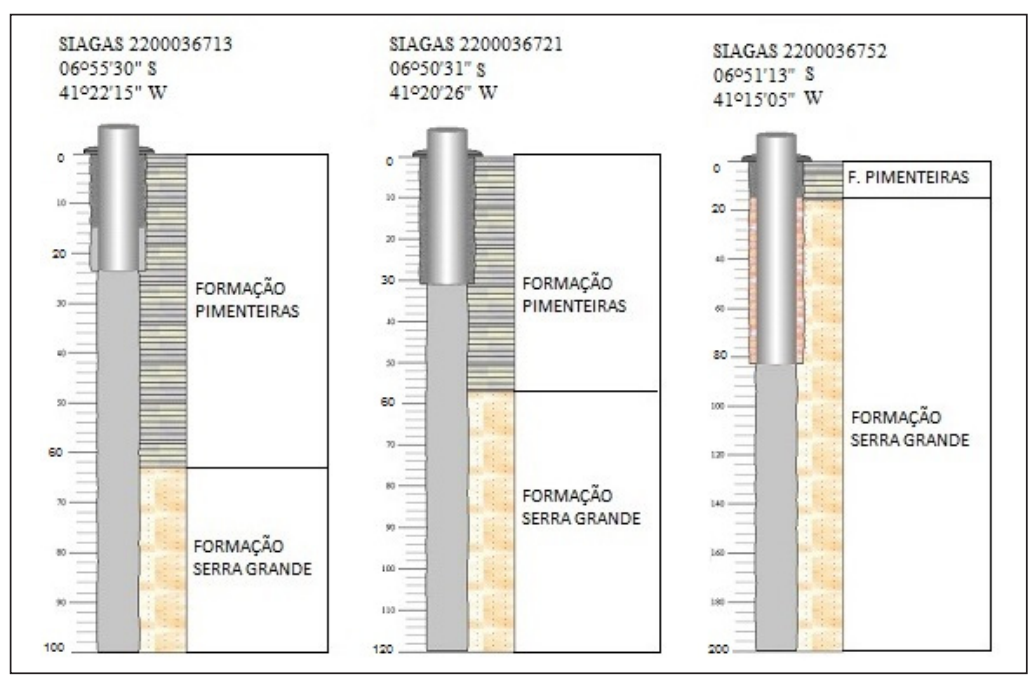

Figura 5 - Perfis Geológicos na área da Bacia da Barragem de Bocaina. Fonte: SIAGAS

a partir de um programa de planejamento, uso e monitoramento dos seus recursos.

$\mathrm{Na}$ região estudada, o Serra Grande apresenta características de um aquífero confinado drenante, encontrando-se recoberto pela Formação Pimenteiras em toda a área, sempre em contato com os sedimentos arenosos do membro Itaim, que fica na parte inferior desta formação (SILVA et al.,2012). A recarga do aquífero ocorre, principalmente, através da infiltração direta das precipitaçôes pluviométricas na zona de afloramento da formação, situada na borda leste da bacia, e pelas águas provenientes do membro inferior do aquitardo Pimenteiras, o Itaim, a partir da infiltração vertical descendente.

A Formação Pimenteiras, devido à sua litologia argilosa, possui baixa permeabilidade e é responsável pelo confinamento do aquífero Serra Grande. Todavia, níveis arenosos de pouca espessura ocorrem intercalados, acumulam água e constituem horizontes aquíferos. De um modo geral, os poços perfurados em seus domínios apresentam resultados insatisfatórios, com baixa produtividade e com água geralmente salobra. O nível estático destes poços apresenta variaçóes sazonais, com rebaixamento durante o período seco. Sua recarga proveniente da infiltração direta das águas das chuvas e dos rios é reduzida devido ao baixo índice pluviométrico registrado na região e a natureza predominantemente argilosa do material da sua área de afloramento.

\section{MATERIAL E MÉTODOS}

Para a realização do monitoramento e análise do nível de água subterrânea e das precipitaçôes foi necessário um levantamento de dados estruturados através de leituras mensais dos níveis de água nos poços e pluviômetros na regiáo em estudo. Enfatizando que a estação pluviométrica em questão está localizada na área próxima ao vertedouro da Barragem e é vinculada ao DNOCS. Para tanto, foram utilizados seis poços localizados nas margens da Barragem de Bocaina, escolhidos obedecendo a critérios como: distribuição geográfica e proximidade dos poços com a Barragem, conforme mostrado na Figura 4. As características de cada poço estão descritas na Tabela 1, em que a terceira coluna mostra o nível de água medido a partir da boca do poço e a quinta coluna apresenta a altitude da boca do poço.

As séries de variação de nível de água dos poços e os dados de precipitações utilizados nas análises foram estudados entre os anos de 2013 até 2015 com periodicidade mensal. Estas séries subsidiaram a consolidação de informações necessárias ao monitoramento integrado das águas superficiais e subterrâneas da região e possível conexão no comportamento existente entre estas. Os padrões resultantes foram observados através de gráficos relacionando o volume da Barragem de Bocaina e o nível de água subterrânea em cada poço ao longo 
Valença J.M.M.S; Cabral J.J.S.P; Santos S.M; Neto G.F; Gil M.L. $\cong$ Análise integrada do nível de água..

Tabela 1 - Dados dos poços

\begin{tabular}{|c|c|c|c|c|}
\hline Poços & Localização & N.A. (m) & Profundidade $(\mathrm{m})$ & Altitude (m) \\
\hline P1 & 6054’32”S 4119'10"O & 15,67 & 110 & 265,67 \\
\hline $\mathrm{P} 2$ & 654’26”S 41¹8’55”O & 22,59 & 110 & 275,08 \\
\hline P3 & 654’2,36”S 41¹9’3,55”O & 29,20 & 110 & 284,71 \\
\hline $\mathrm{P} 4$ & 6053’1”S 41¹9’25”O & 32,24 & 110 & 286,65 \\
\hline P5 & 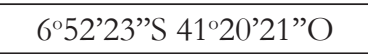 & 22,00 & 110 & 286,17 \\
\hline P6 & 6053’42”'S 41¹8’04”O & 32,24 & 110 & 300 \\
\hline
\end{tabular}

dos 3 anos produzindo um diagnóstico importante na dinâmica do equilíbrio hídrico integrado superficial e subterrâneo da região.

Nesse contexto, analisou-se a influência da precipitação no volume da Barragem e no nível de água dos poços da região, as variações extremas de armazenamento subterrâneo e a distribuição pluviométrica ao longo dos anos.

Adicionalmente, para avaliar melhor a influência da precipitação no aquitardo Pimenteiras e consequente resposta no aquífero Serra Grande, foram realizados ensaios de granulometria na camada superficial do solo descrevendo a constituição deste no entorno e no leito da Barragem.

\section{RESULTADOS E DISCUSSÃO}

\section{Análise da Precipitação}

De acordo com Rebouças (1997), a precipitação pluviométrica no semiárido nordestino, pode ocorrer em um mês ou distribuídas de forma irregular, 3 a 5 meses chuvosos no ano. A precipitação anual na área estudada nos anos de 2013, 2014 e 2015 foram respectivamente $164 \mathrm{~mm}, 471 \mathrm{~mm}$ e $379 \mathrm{~mm}$. Na comparação entre os períodos chuvosos e de estiagem observa-se a concentração pluviométrica nos meses de dezembro a abril, salientando que nos meses de fevereiro e março a intensidade foi maior.

Como regra, constata-se a influência da precipitação nos poços estudados através das variaçôes de níveis estáticos observados após os eventos. Essa alteração no nível subterrâneo permite inferir a existências de caminhos descritos pela água no processo de infiltração ultrapassando o aquitardo Pimenteiras e alimentando o aquífero Serra Grande.
Todos os gráficos demonstraram o reflexo de melhores respostas dos aquíferos a chuvas melhor distribuídas ao longo do tempo em detrimento dos picos de precipitação de chuvas torrenciais.

Em tempo, o estudo relizado por Gouvêa (2009) confirma a influência da sazonaliade pluviométrica nos níveis d'água nos poços monitorados, mostrando uma forte dependência dessas variáveis através do estudo das correlaçôes das séries de dados. Também descreve nas suas conclusóes que os níveis estáticos dos poços não respondem imediatamente aos eventos de precipitação.

\section{Análise da Precipitação e do Volume da Barragem}

Em primeira análise, conforme o gráfico apresentado na Figura 6, o comportamento do volume da Barragem acompanha o volume precipitado durante o período estudado. Nos meses de ocorrência de chuva a quantidade de água do reservatório apresenta um acréscimo no seu volume.

No que diz respeito ao volume da Barragem ao final de cada ano constata-se que, mesmo acontecendo uma recuperação parcial no período de chuva, o nível de água na Barragem tem diminuído ano a ano.

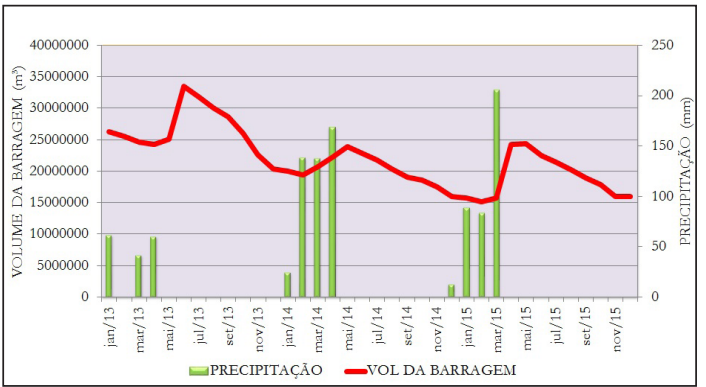

Figura 6 - Variação do nível de água da Barragem e precipitações 
Entre os fatores que influenciam esse declínio, além da diminuição da precipitação, estão os efeitos da evaporação e o uso múltiplo da água da Barragem.

\section{Análise da Precipitação e dos Níveis Estáticos dos Poços}

As Figuras 7 a 12 mostram que os níveis de água subterrânea oscilaram durante o período estudado, com aumento destes em resposta aos eventos de precipitação e diminuição nos períodos de estiagem. Observa-se também que os níveis de água subterrânea no final de cada ano decrescem e que sua elevação se dá de forma mais acentuada num ano que a precipitação acumulada for maior, caracterizando um comportamento de recarga parcial do aquífero.

No poço 5 (Figura 11), ao final do período de monitoramento, observou-se que o nível estático do poço diminuiu consideravelmente se comparado ao início do monitoramento em 2013. O nível de água subterrânea neste poço iniciou em janeiro de 2013 com cota de 263,32 m e apresentou em dezembro de 2015 cota de $260,96 \mathrm{~m}$.

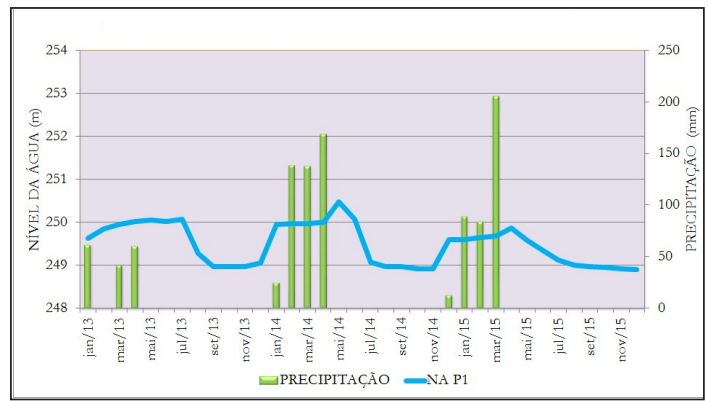

Figura 7 - Variação do nível de água no poço 1 e precipitações

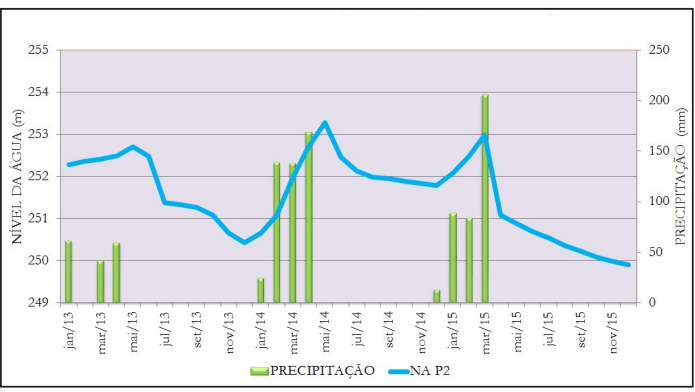

Figura 8 - Variação do nível de água no poço $2 \mathrm{e}$ precipitações

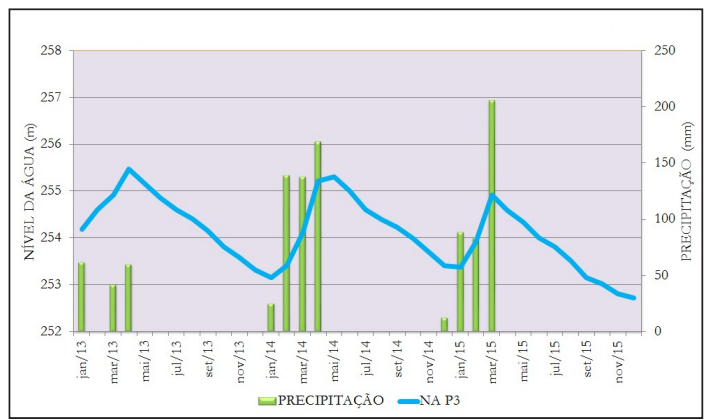

Figura 9 - Variação do nível de água no poço 3 e precipitações

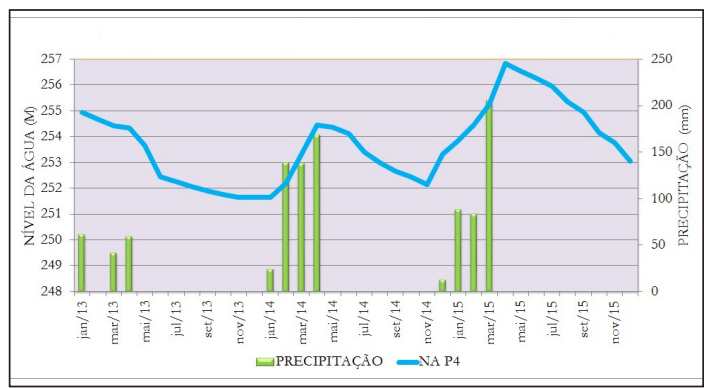

Figura 10 - Variação do nível de água no poço $4 \mathrm{e}$ precipitações

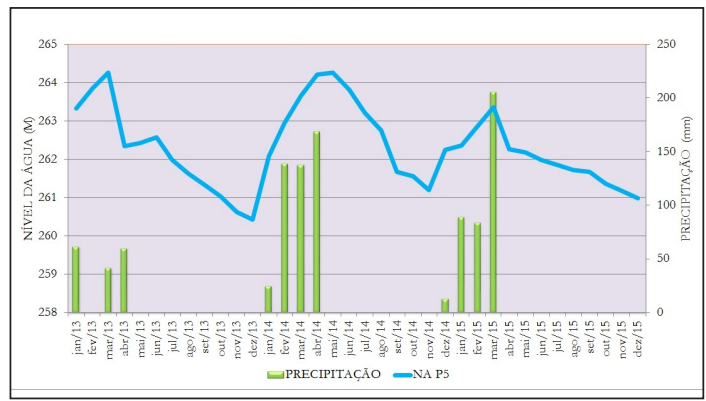

Figura 11 - Variação do nível de água no poço $5 \mathrm{e}$ precipitações

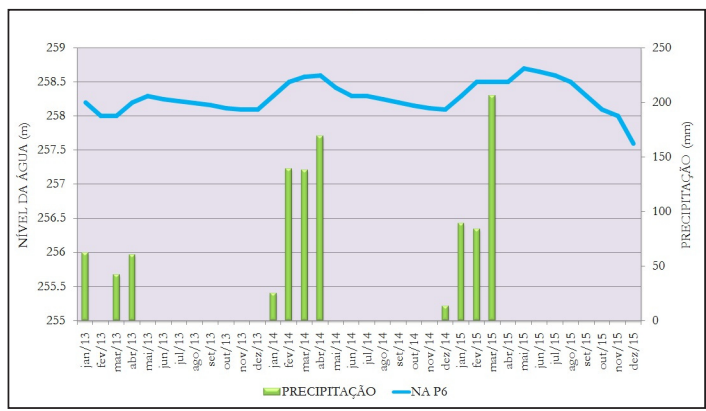

Figura 12 - Variação do nível de água no poço $6 \mathrm{e}$ precipitações 


\section{ANÁLISE DOS NÍVEIS ESTÁTICOS DOS POÇOS E DO NÍVEL DE ÁGUA DA BARRAGEM}

Em geral, os níveis das águas da Barragem e dos poços apresentados nas Figuras 13 a 18 descrevem um padrão de comportamento com reflexos resultantes dos períodos secos e chuvosos. De maneira mais lenta, os níveis dos poços respondem com uma variação moderada a períodos curtos de estiagem, enquanto que a Barragem diminui acentuadamente seu volume. Assim também no período chuvoso o nível da água da Barragem responde ascendentemente de maneira mais rápida que os níveis de água subterrânea nos poços.

Como descrito por Lobler (2015), no seu estudo, as maiores variaçôes dos níveis d'água subterrâneos aconteceram no inverno, período de maior intensidade de chuvas, menor evapotranspiração, menor insolação e maior permanência de unidade na zona aerada, com chuvas melhor distribuídas ao longo desse tempo. Através do estudo de Gouvêa (2009) é possível afirmar que eventos isolados de precipitação não geram variaçóes dos níveis d'água nos poços, e sim valores de precipitaçáo acumulada ao longo do tempo que determinam essas elevaçóes.

No poço 6 (Figura 18), diferente dos outros poços, o nível estático quase não varia nos períodos de chuva e estiagem. Contudo, foi observado que, em 2013, este nível encontra-se abaixo do nível de água da Barragem, mas a partir de 2014, quando a Barragem tem seus níveis mais baixos, o nível do poço 6 atinge cota superior ao nível de água da Barragem. Com um comportamento constante, é possível que o nível de água do poço 6 não responda aos eventos de precipitação. Desta forma, na área do poço 6 o nível de água do aquífero praticamente não responde à precipitação, nem responde ao nível de água da Barragem.

Estabelecendo uma comparação entre os níveis de água subterrânea e da Barragem (Figura 19), observa-se um comportamento similar quanto às respostas destes nos períodos chuvosos e de estiagem, com exceção do poço 6 que tem comportamento independente dos períodos de chuva e estiagem.

Além da precipitação, diversos elementos influenciam a dinâmica dos níveis de água dos poços. Fatores como topografia, uso e ocupaçáo do solo, geologia, espessura e inclinação das camadas de solo, condutividade hidráulica,

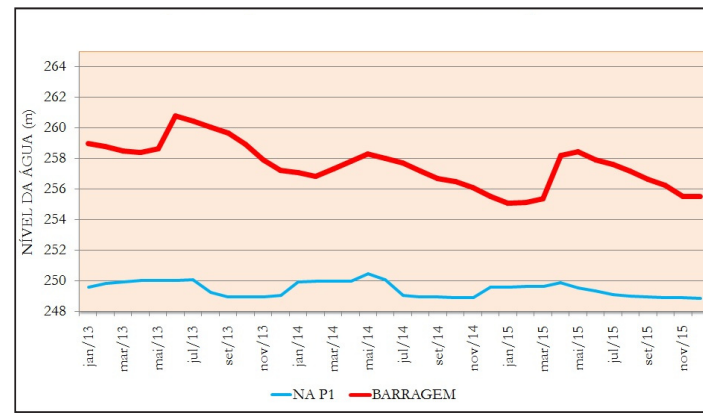

Figura 13 - Variação do nível de água do poço 1 e da Barragem

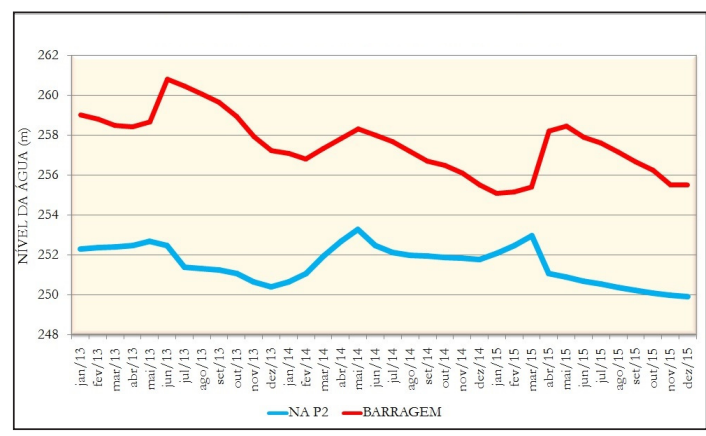

Figura 14 - Variação do nível de água do poço 2 e da Barragem

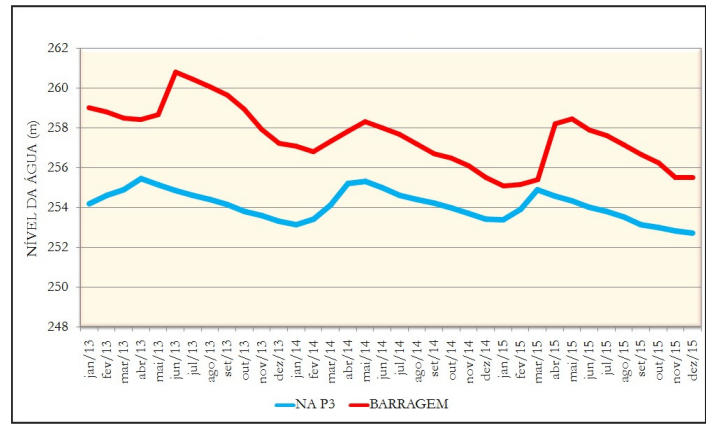

Figura 15 - Variação do nível de água do poço 3 e da Barragem

granulometria da camada superficial do solo, entre outros, compóem um conjunto de agentes modificadores da variação no volume de água subterrânea numa região.

Considerando que a infiltração média numa bacia corresponde à diferença entre a precipitação e o escoamento superficial direto, e que parte da água que infiltra fica na zona não saturada, podendo sair do sistema por evapotranspiração, esta também interfere 
na disponibilidade hídrica subterrânea e pode inclusive ser calculada a partir da variação do nível do aquífero (BARRETO; WENDLAND; MARCUZZO, 2009). Segundo os estudos de Maziero (2005), a recarga é limitada, em grande parte, pela água disponível na superfície do terreno, controlada por fatores climáticos, como a precipitação e a evapotranspiração e pelas características geomorfológicas (topografia, solo e cobertura vegetal).

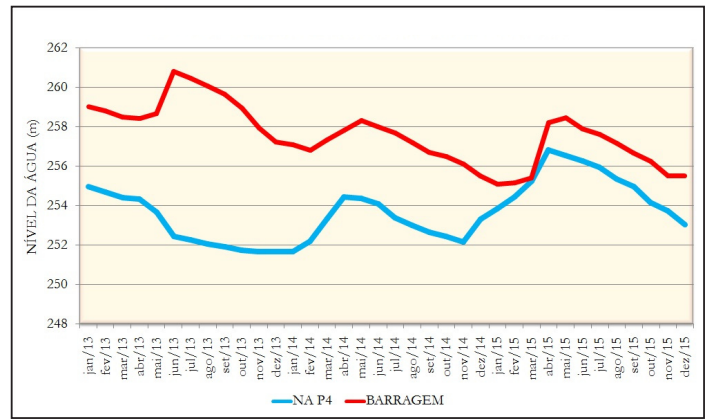

Figura 16 - Variação do nível de água do poço 4 e da Barragem

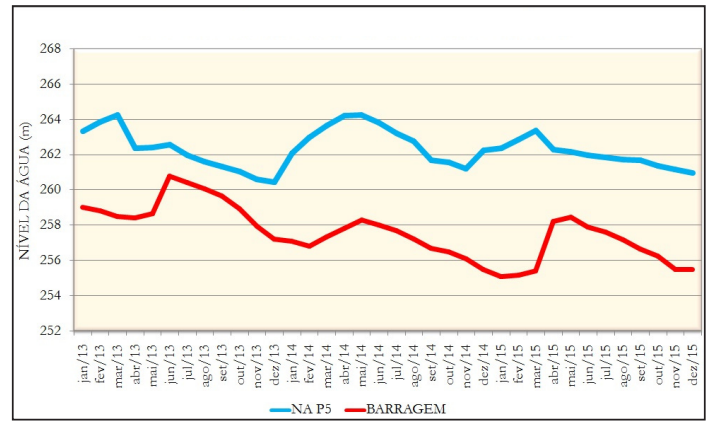

Figura 17 - Variação do nível de água do poço 5 e da Barragem

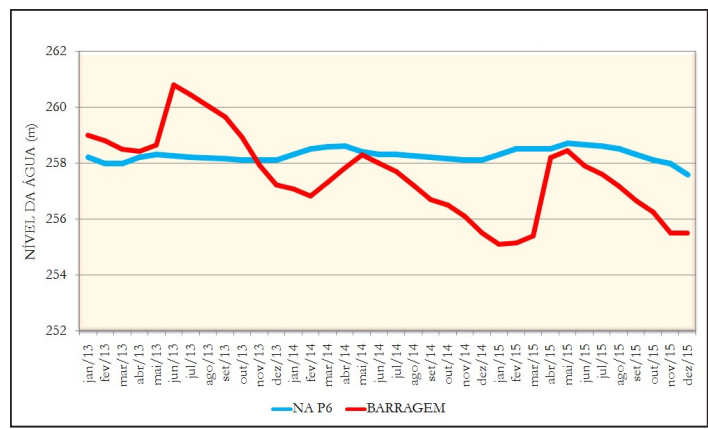

Figura 18 - Variação do nível de água do poço 6 e da Barragem

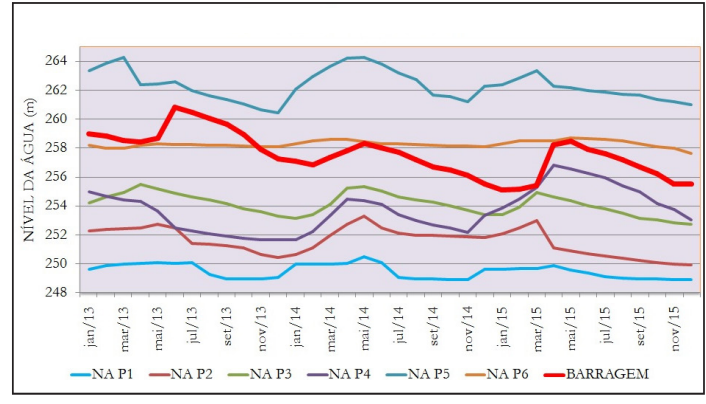

Figura 19 - Variação do nível de água dos poços

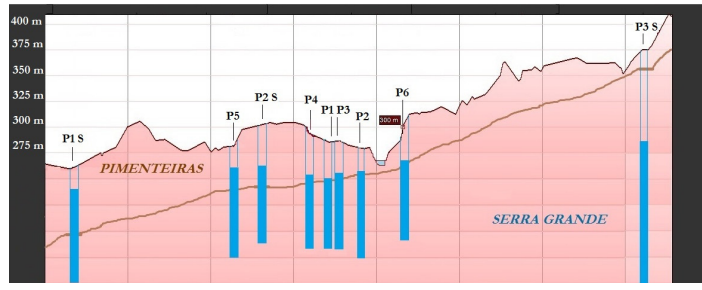

Figura 20 - Corte esquemático da área em estudo

Com o relevo ondulado e altitudes das bocas dos poços variando de 248 até 300m (Figura 20), verificou-se que o comportamento do poço 6 é largamente influenciado pela sua localização (margem leste da Barragem) e com isso seu nível não apresenta variaçóes significativas relacionadas aos períodos de chuva e estiagem. Com altitude de $300 \mathrm{~m}$, este poço encontra-se numa região íngreme com declividade acentuada induzindo uma maior velocidade de escoamento superficial, com menor tempo de concentração e consequentemente menor inflitração do volume precipitado. Santos e Pereira (2013) afirmam que a forma do relevo pode influenciar nas taxas de infiltração, pois regióes de topografias planas ou relativamente planas absorvem a maior parte das águas precipitadas sobre o solo, resultando em menores volumes de água para o escoamento superficial, e como consequência maior possibilidade de recarga.

\section{Análise da Granulometria na camada superficial do solo}

Nos ensaios de granulometria realizados com a camada superficial do solo constatou-se a presença 
de $20 \%$ de pedregulho, $68 \%$ de areia, $8 \%$ de silte e $4 \%$ de argila na constituição dos solos no entorno da Barragem. Considerando que existe influência das características do solo na variação do nível da água nos poços, esses dados podem explicar a influência da porosidade no processo de infiltração da água no solo. Já nas amostras no leito da Barragem o solo é composto de $85 \%$ de argila e $5 \%$ de silte, carcaterizando um solo propenso à baixa infiltração.

As diferenças no processo de infiltração de água estão associadas às frações granulométricas do solo, à quantidade, à espessura, ao ângulo e ao preenchimento das fraturas na camada superficial e às condiçóes de relevo e uso atual do solo, destacando com isso a importância da análise granulométrica (STÜRMER et al., 2009). Paes (2014) ressalta a relevância do conhecimento das propriedades físicas do solo para entendimento da sua dinâmica hídrica. Os percentuais de areia, argila e silte e características como porosidade e densidade influenciam direta e indiretamente o comportamento de recarga (BABALOLA, 1978). Segundo Rizzardi et al., (2014), o maior valor de porosidade proporciona uma maior permeabilidade ao fluxo de água; de modo geral, os maiores valores de condutividade hidráulica saturada tendem a ser encontrados juntamente com os maiores valores de porosidade total.

\section{CONCLUSÃO E RECOMENDAÇÕES}

No estudo em questão foi realizada uma análise integrada das variaçóes dos corpos hídricos superficiais e subterrâneos. Para tanto foi realizado o monitoramento conjunto dos níveis de água subterrânea no aquífero Serra Grande e nos níveis de água da Barragem de Bocaina, assim como a análise granulométrica da camada superficial do solo. Durante esse tempo foi detectado que o aquitardo Pimenteiras, que confina o aquífero Serra
Grande, sofre influência das precipitaçóes transmitindo esse comportamento para o aquífero Serra Grande.

$\mathrm{Na}$ margem direita da Barragem, no poço 6, a influência da precipitação é quase nula descrevendo um comportamento relativamente constante no nível estático de água do poço durante os três anos, presumindo que este seja influenciado pela declividade acentuada do terreno que induz a uma alta velocidade de escoamento superficial e consequentemente baixa infiltração da água da chuva na região.

Observando o nível de água da Barragem, este descreve um comportamento análogo ao descrito nos níveis de água dos poços, de maneira mais rápida e acentuada, com exceção do poço 6 que praticamente não varia de nível piezométrico.

A análise granulométrica da camada superficial do solo contribuiu para confirmar a influência da infiltração da água proveniente da precipitação no aquitardo Pimenteiras, e deste no aquífero Serra Grande. Justificando que, mesmo com baixa permeabilidade na camada superior da Formação Pimenteiras, os níveis arenosos de pouca espessura que ocorrem intercalados, que acumulam água e constituem importantes horizontes aquíferos, armazenam e transmitem água para o aquífero Serra Grande no entorno da Barragem Bocaina.

A frequência do monitoramento adotada foi satisfatória para acompanhar as respostas na elevação e decréscimo do nível estático do aquífero e na Barragem decorrentes das precipitaçóes e para avaliar a dinâmica integrada de ambos no que diz respeito a possíveis conexôes e direcionamento de fluxo. Visando a sustentabilidade hídrica local e levando em consideração as interaçôes entre a precipitação, o volume armazenado na Barragem e os níveis do aquífero, verifica-se que a gestão adequada dos recursos hídricos deve utilizar uma abordagem integrada das diferentes fontes de água.

\section{Referências}

AGÊNCIA NACIONAL DE ÁGUAS - ANA. Sistema Nacional de Informações sobre Recursos Hídricos/SNIRH. Hidroweb. Disponível em: <http://www.snirh.gov.br/>. Acesso em: 10 dez. 2017.

ALLEN, D. M. et al. Variability in simulated recharge using different GCMs. Water Resources Research, 2010. v. 46, n. 10. Disponível em: <http://onlinelibrary.wiley.com/doi/10.1029/2009WR008932/full>. Acesso em: 10 out. 2014. 
ANDRADE JÚNIOR, A. S. et al. Aqüifero Serra Grande: uso da água e forma de exploração. In: CONGRESSO BRASILEIRO DE ENGENHARIA AGRÍCOLA, 32., 2003, Goiânia, GO. Novas fronteiras: o desafio da engenharia agrícola. Goiânia: SBEA, 2003. Disponível em: <https:// www.alice.cnptia.embrapa.br/bitstream/doc/15028/1/2003AA012.pdf>. Acesso em: 20 out. 2017.

BABALOLA, O. Spatial variability of soil water properties in tropical soils of Nigeria. Soil Science, 1978. v. 126, n. 5, p. 269-279. Disponível em: <http://journals. Iww.com/soilsci/abstract/1978/11000/spatial_variability_of_soil_water_properties_in.3.aspx>. Acesso em: 27 dez. 2016

BARRETO, C. E. A. G.; WENDLAND E.; MARCUZZO F. F. N. Estimativa da evapotranspiração a partir de variação de nível estático de aquífero. Engenharia Agrícola, 2009. v. 29, n.1, pp.52-61. Disponivel em: <http://www.scielo.br/pdf/eagri/v29n1/a06v29n1.pdf>. Acesso em: 9 jul. 2015.

BRASIL. Resolução CNRH no 15 de 11 de janeiro de 2001. Brasília, DF, 2008. Estabelece diretrizes gerais para a gestão de águas subterrâneas. Diário Oficial da União, Brasilia, 12 de jan. 2001. Disponivel em: <http://www.cnrh.gov.br/index.php?option=com content\&view=article\&id=14>. Acesso em: 12 jan. 2014.

CRUZ, W.B.; FRANÇA, H.P.M. Água subterrânea sob condições artesianas na área de Picos-Piauí. Recife: SUDENE, 1967. 79 p.

FEITOSA, E. C.; FEITOSA, F. A. C. Metodologia básica de pesquisa de água subterrânea. In: FEITOSA, F. A. C.; MANOEL FILHO, J.; FEITOSA, E. C.; DEMETRIO, J. G. A. Hidrogeologia: Conceitos e aplicações. Rio de Janeiro: CPRM/LABHID, 2008.

GOUVÊA, T. H. Análise estatística da influência da precipitação e de características do solo na variação do nível d'água em área de recarga do Aquífero Guarani. 2009. 145f. Dissertação (Mestrado). Escola de Engenharia de São Carlos (EESC), USP. São Carlos, SP. Disponível em: <http://www.teses.usp.br/teses/disponiveis/18/18138/tde-17092009-103001/pt-br.php>. Acesso em: 05 dez. 2016.

HIRATA, R.; ZOBY, J.L.G.; OLIVEIRA, F.R.O. Água Subterrânea: reserva estratégica ou emergencial. In: BICUDO, C.; TUNDISI, J.; SCHEUENSTUHL, M. (Org.). Águas do Brasil: análises estratégicas. 1 ed. São Paulo: Instituto de Botânica, 2010. v. 1, p. 144-164. Disponivel em: <https://www.abc.org.br/IMG/pdf/doc-6820.pdf>. Acesso em: 25 nov. 2014.

JYRKAMA, M. I.; SYKES, J. F. The impact of climate change on spatially varying groundwater recharge in the grand river watershed (Ontario). Journal of Hydrology, 2007. v. 338, n. 3, p. 237-250. Disponível em: <https://doi.org/10.1016/j.jhydrol.2007.02.036>. Acesso em: 17 nov. 2014.

KEGEL, W. Estudos no Estado do Piauí. Relatório. Teresina: DNPM, 1953. 18p.

LÖBLER, C. A. Avaliação quantitativa da recarga das águas subterrâneas na bacia escola do campus na Universidade Federal de Santa Maria. 2015. 98f. Dissertação (mestrado). Universidade Federal de Santa Maria. Santa Maria, RS. Disponível em: <http://repositorio.ufsm.br/ handle/1/7644>. Acesso em: 15 jan. 2017.

LORENZO-LACRUZ, J.; GARCIA, C.; MORÁN-TEJEDA, E. Groundwater level responses to precipitation variability in Mediterranean insular aquifers. Journal of Hydrology, 2017. v. 552, p. 516-531. Disponivel em: <https://doi.org/10.1016/j.jhydrol.2017.07.011>. Acesso em: 17 nov. 2014.

MANZIONE, R. L. Águas subterrâneas: conceitos e aplicações sob uma visão multidisciplinar. Jundiaí: Paco Editorial, 2015. 386 p.

MARCUZZO, F. F. N., MANZIONE, R. L.; WENDLAND, E. Efeito do Índice Oceanico Niño no nível freático de aquífero no estado de São Paulo. In: CONGRESSO BRASILEIRO DE ÁGUAS SUBTERRÂNEAS, 17., 2012, Bonito, MS. Anais eletrônicos... São Paulo, SP: ABAS, 2012. Disponivel em: <https://aguassubterraneas.abas.org/asubterraneas/article/view/27718>. Acesso em: 15 jul. 2015. 
Valença J.M.M.S; Cabral J.J.S.P; Santos S.M; Neto G.F; Gil M.L. $\cong$ Análise integrada do nível de água..

MARCUZZO, F. F. N.; TROIAN G. C.; GOFFERMANN, M. Correlação do Índice Oceânico Niño com a profundidade do nível d'água em aquífero no Rio Grande do Sul. 2012. 4p. XVII Congresso Brasileiro de Águas Subterrâneas e XVIII Encontro Nacional de Perfuradores de Poços. Disponivel em: <http://rigeo.cprm.gov.br/jspui/bitstream/doc/1133/1/evento_marcuzzo_nino.pdf>. Acesso em: 01 nov. 2016.

MARTELLI, G. V. Monitoramento da flutuação dos níveis de água em aquíferos freáticos para avaliação do potencial de recarga em área de afloramento do sistema aquífero guarani em CACEQUI - RS. 2012. 151p. Dissertação (Mestrado em Engenharia Civil e Ambiental) - Universidade Federal de Santa Maria, Santa Maria, RS. Disponível em: <http://repositorio.ufsm.br/handle/1/7788>. Acesso em: 15 set. 2014.

MAZIERO, T. A. Monitoramento de água subterrânea em área urbana: aspectos quantitativos. 2005. 236f. Dissertação (Mestrado em Hidráulica e Saneamento). Escola de Engenharia de São Carlos (EESC) - USP. São Carlos, SP. Disponivel em: <http://www.teses.usp.br/teses/ disponiveis/18/18138/tde-06102017-154832/pt-br.php>. Acesso em: 16 set. 2014.

MESNER, J. C.; WOOLDRIDGE, L. C. Estratigrafia das bacias paleozoica e cretácea do Maranhão. Tradução e condensação de Carlos Walter Marinho Campos. In: PAULA, A. C. M. (Sup.). Boletim técnico da Petrobras. Rio de Janeiro: PETROBRAS, 1964, v. 7 n. 2 p. $137-164$. Disponivel em: <http://publicacoes. petrobras.com.br/main.jsp?lumPageld=8A9E308F545405DE0154A04B46AD0C9E \&lumltemld=8A9D2A985E19B9DD015E9AEF382A67FB\&previewltemld=8A9D2A985E19B9DD015E9AEF382767 FA\&publicacaold=8A9D2A975A1AAE8B015AAF320FF333D7>. Acesso em: 23 abr. 2015.

MESTRINHO, S. S. P. Monitoramento em água subterrânea. In: FEITOSA, F. A. C.; MANOEL FILHO, J.; FEITOSA, E. C.; DEMETRIO, J. G. A. Hidrogeologia: Conceitos e aplicações. Rio de Janeiro: CPRM/LABHID, 2008. p. 673-686.

PAES, C O. Modelagem espacial de áreas de recarga subterrânea em região de afloramento do sistema aquifero guarani (SAG), em Brotas/ SP. 2014. xii, 87 f. Dissertação (mestrado) - Universidade Estadual Paulista Júlio de Mesquita Filho, Faculdade de Ciências Agronômicas de Botucatu. Botucatu, SP. Disponivel em: <http://hdl.handle.net/11449/123232>. Acesso em: 30 set. 2017.

REBOUÇAS, A. C. Água na região Nordeste: desperdício e escassez. Estudos avançados. São Paulo. 1997. v. 11, p. 127-154, n 29. Disponível em:<http://www.scielo.br/scielo.php?script=sci_arttext\&pid=S0103-40141997000100007>. Acesso em: 11 nov. 2013.

RIZZARDI, A. S. et al. Atributos físicos e fluxo de água em solos da bacia hidrográfica do rio Vacacai-Mirim - RS. Revista Monografias Ambientais, 2014. v. 13, p. 3690-3701. Disponível em: <https://periodicos.ufsm.br/remoa/article/viewFile/14260/pdf>. Acesso em: 29 set. 2017.

SANTOS, J. N.; PEREIRA, E. D. Carta de susceptibilidade a infiltração da água no solo na sub-bacia do rio Maracanã - MA. Cadernos de Pesquisa, São Luís, 2013. v. 20, n. especial. Disponivel em: <http://www.periodicoseletronicos.ufma.br/index.php/ cadernosdepesquisa/article/view/1758>. Acesso em: 25 jan. 2017.

PIAUÍ (Estado). Secretaria de Meio Ambiente e Recursos Hídricos. Relatório final de serviço de criação de modelo geoidal local para o açude Bocaina. Biblioteca da Secretaria de Meio Ambiente e Recursos Hídricos do Estado do Piauí. Elaborado por Geoffshore Engenharia e Serviços Marítimos Ltda. Teresina, PI: 2016.

SILVA, R. C.; DOMINATO, V. H.; FERNANDES, A. C. S. Novos registros e aspectos paleoambientais dos icnofósseis da Formação Pimenteiras, Devoniano da Bacia do Parnaíba, Piauí, Brasil. Gaea - Journal of Geoscience, 2012. v. 8, n. 1, p. 33-41. Disponível em: <http://revistas. unisinos.br/index.php/gaea/article/view/4230>. Acesso em: 9 out. 2016.

STÜRMER, S. L. K. et al. Relação da granulometria do solo e morfologia do saprolito com a infiltração de água em Neossolos Regolíticos do

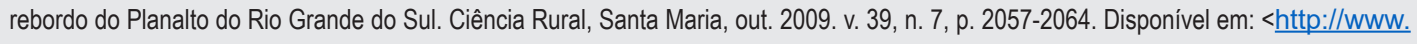
scielo.br/pdf/cr/2009nahead/a276cr1274.pdf>. Acesso em: 15 out. 2016. 
VASCONCELOS, M. B. et al. Histórico das Perfurações de Poços Tubulares no estado do Piauí. Revista de Geologia, 2014. v. 27, n. 2, p. 111126. Disponivel em: <http://www.periodicos.ufc.br/index.php/geologia/article/download/1296/1228>. Acesso em: 7 jan. 2017.

WINTER, et al. Ground Water and Surface Water a Single Resource. U.S. Denver, Colorado, EUA. 1998. Geological Survey circular: 1139, 87p. Disponivel em: <https://pubs.usgs.gov/circ/circ1139/pdf/circ1139.pdf>. Acesso em: 15 out. 2015.

TUCCI, C. E. M., 1993. Hidrogeologia Ciência e Aplicação, ABRH - Associação Brasileira de Recursos Hídricos, 941 p.

VIDAL, C. L. R. Disponibilidade e gerenciamento Sustentável do Aquífero Serra Grande no Município de Picos - Piauí, 2003. 208f. Tese (Doutorado em Recursos Minerais e Hidrogeologia). Universidade de São Paulo, Instituto de Geociências. São Paulo, SP. Disponível em: <http://www.teses.usp.br/teses/disponiveis/44/44133/tde-20112004-114121/pt-br.php>. Acesso em: 10 jan. 2015.

ZOBY, J. L. G.; MATOS, B. Águas subterrâneas no Brasil e sua inserção na Política Nacional de Recursos Hídricos. In: CONGRESSO BRASILEIRO DE ÁGUAS SUBTERRÂNEAS, 2002, 12., n.1, p.1-19. Florianópolis, SC. Anais eletrônicos. São Paulo, SP: ABAS, 2002. Disponivel em: <https://aguassubterraneas.abas.org/asubterraneas/article/view/22634>. Acesso em: 10 abr. 2016.

Juliana M. de M. S.Valença Universidade Federal do Pernambuco, Recife, PE, Brasil. E-mail: Julimsv@outlook.com

Contribuição do autor:

Concepção do trabalho, artigo resultante de parte da tese de doutorado da autora, Levantamento bibliográfico, compilação dos dados, redação do manuscrito.

Jaime J. da S. P. Cabral Universidade Federal do Pernambuco, Recife, PE, Brasil. E-mail: Jcabral@ufpe.br

Contribuição do autor:

orientador da tese de doutorado da autora, discussão dos dados coletados, revisão do levantamento bibliográfico e revisão do manuscrito

Sylvana Melo Dos Santos Universidade Federal de Pernambuco,

Recife, Pe, Brasil. E-mail: Sylvana.ufpe@gmail.com

Contribuiçáo do autor:

co-orientadora da tese de doutorado da autora, discussão dos dados coletados, revisão do levantamento bibliográfico e revisão do manuscrito.

Gastáo Fonseca Neto Universidade Federal de Pernambuco, Recife, PE, Brasil. E-mail: Gastaocerquinha@gmail.com Contribuição do autor:

discussão dos dados coletados, revisão do levantamento bibliográfico e revisão do manuscrito.

Margarita Lopez Gil Universidade Estadual do Piauí, Teresina, PI, Brasil. E-mail: margot.rd@gmail.com Contribuição do autor:

discussão dos dados coletados, revisão do levantamento bibliográfico e revisão do manuscrito. 